\title{
PROPRIEDADES DE ÓLEOS EMPREGADOS EM FLOTAÇÃO
}

\author{
I. A. M SOUZA' e J. A. M. LUZ \\ ${ }^{1}$ Licenciado em Matemática e acadêmico de Engenharia de Minas (DEMIN/UFOP) \\ ${ }^{2}$ Engenheiro de Minas (professor associado do DEMIN/UFOP) \\ Igor.albertomsouza@gmail.com¹; jaurelioluz@gmail.com²
}

Artigo submetido em novembro/2013 e aceito em março/2014

DOI: http://dx.doi.org/10.15628/holos.2014.1800

\section{RESUMO}

Neste trabalho se buscou a sistematização das características de quatro amostras de óleos vegetais e uma amostra de sebo bovino, no que concerne a suas propriedades físico-químicas como com o fito de estabelecer padrões de comportamento e de desempenho em sistemas de flotação. Os óleos vegetais estudados foram: de arroz refinado, de rícino, de semente de uva e de soja refinado, usualmente empregados em operações de tecnologia mineral, com ênfase em seu uso em sistemas de flotação em espuma. As massas específicas determinadas foram: $930 \mathrm{~kg} / \mathrm{m}^{3}$ para o óleo de semente de uva; $950 \mathrm{~kg} / \mathrm{m}^{3}$ para o óleo de rícino; $910 \mathrm{~kg} / \mathrm{m}^{3}$ para o óleo de arroz refinado; e 920 $\mathrm{kg} / \mathrm{m}^{3}$ para o óleo de soja. Quanto à tensão superficial foram realizados 26 ensaios para cada amostra de óleo vegetal sendo que os valores variam de $0,0323 \mathrm{~N} / \mathrm{m}$ a $0,0334 \mathrm{~N} / \mathrm{m}$. Viscosidade dinâmica aparente, tensão superficial, índice de refração e valores de umidade também foram levantados. Os resultados permitiram aceder às propriedades das amostras e confrontá-las com as que se descrevem na literatura, servindo, assim, como subsidio ao entendimento da influência destas propriedades na flotação.

PALAVRAS-CHAVE: óleos vegetais, flotação aniônica, tensão superficial, caracterização físico-química.

\section{PROPERTIES OF OILS USED IN FLOTATION}

\section{ABSTRACT}

This paper tried to systematize some physical-chemical properties of four vegetable oils samples and one tallow sample, aiming ultimately to establish behavior patterns in flotation systems. The flowing vegetable oils were studied: refined rice, castor, grape seed and soy oil. These oils are usually employed in mineral technology operations, with emphasis on froth flotation systems. The densities were determined: $930 \mathrm{~kg} / \mathrm{m}^{3}$ for grape seed oil; $950 \mathrm{~kg} / \mathrm{m}^{3}$ to castor oil; $910 \mathrm{~kg} / \mathrm{m}^{3}$ to refined rice bran oil, and $920 \mathrm{~kg} / \mathrm{m}^{3}$ for soybean oil. As to surface tension is concerned 26 tests were performed for each sample of vegetable oil and the values ranging from $0.0322 \mathrm{~N} / \mathrm{m}$ to $0.0334 \mathrm{~N} / \mathrm{m}$. Apparent dynamic viscosity, surface tension and refractive indices were also surveyed. The results allowed us to know the samples' features and compare them with those showed in the literature, thus serving as a subsidy to the understanding of the influence of these properties on flotation systems. 


\section{INTRODUÇÃO}

Óleos e gorduras, especialmente os de origem vegetal, desempenham papel importante como matérias-primas no âmbito da tecnologia mineral. A importante classe dos coletores aniônicos, por exemplo, pode ser bem representada por ácidos graxos e seus sabões, majoritariamente obtidos de óleos e gorduras. As gorduras distinguem-se dos óleos por serem sólidas à temperatura ambiente, ao passo que os últimos são líquidos nessas condições. Em qualquer caso, essas substâncias, predominantemente, podem ser formalmente consideradas como constituídas de produtos da condensação química entre glicerol e ácidos graxos, formando triésteres, ditos triglicérides (Moretto e Alves, 1986; Jamieson, 1943). O ácido graxo por excelência associado aos triésteres de óleos vegetais é o oleico (ácido cis-9-octadecenoico).

Os óleos vegetais, como de soja, de arroz, de semente de uva, de rícino, ou o tall oil (extraído do Pinus eliotti), são muito empregados em flotação, geralmente após sua saponificação com soda cáustica $(\mathrm{NaOH})$ ou hidróxido de potássio $(\mathrm{KOH})$. Por vezes empregam-se tais óleos in natura ou em mistura com seus sabões.

O sebo também pode ser usado com o mesmo propósito, embora nesse caso o mais comum seja o seu consórcio com óleos vegetais, ou outros coletores sintéticos, em função da baixa solubilidade de seus sais, decorrente de cadeias carbônicas maiores e maior índice de saturação (ligações simples entre carbonos).

As propriedades físico-químicas dessas matérias-primas geralmente acham-se consignadas na literatura técnica, embora de modo grandemente errático e disperso; e, assim mesmo, com o enfoque de natureza da indústria química e/ou alimentícia (consultem-se, por exemplo: Jamieson, 1943; Brasil, 1985; Fornazieri, 1986; Moretto e Alves, 1986; Azevedo, 1994; Caires, 1992). Ademais disso, essas propriedades são largamente dependentes dos cultivares e cepas biológicas de onde foram extraídos, levando a grande dispersão estatística dos valores, em face da grande variabilidade genética das plantas, bem como da variabilidade climática e edáfica dos solos cultivados.

Em função disso, este trabalho buscou a sistematização das características de quatro amostras de óleos e uma amostra de sebo bovino, no que concerne a suas propriedades físicoquímicas como densidade, viscosidade, tensão superficial e índices de refração, com o fito de estabelecer padrões de comportamento e de desempenho em sistemas de flotação.

\section{MATERIAIS E MÉTODOS}

Na elaboração dos ensaios de densitometria dos óleos de arroz refinado, rícino (mamona), semente de uva e soja refinado fez uso de picnômetros e balança de precisão Shimadzu AUW220D. Concomitante aos ensaios, foram lidos a temperatura ambiente através de termômetro de mercúrio e o potencial hidrogeniônico $(\mathrm{pH})$ de cada amostra através do peagômetro DM - 22, da Digimed. A metodologia empregada foi a picnometria clássica encontrada nos livros textos de mineralogia e de experimentação físico-química, como, por exemplo, Shoemaker e colaboradores (1996). Entretanto, a correção devida ao empuxo arquimediano da atmosfera não foi feita. 
Na realização dos ensaios de determinação da tensão superficial foi utilizado o tensiômetro K6 da Krüss, onde se realizaram 26 ensaios (determinações) para cada uma das amostras.

O viscosímetro DV-I Prime da Brookfield foi utilizado nos ensaios de viscosimetria, nos quais se faziam leituras de viscosidade, velocidade angular e fração de torque. Para tal ensaio foram utilizados diferentes fusos (LV1 - S61, LV2 - S62 e ULA - S00) para a mesma amostra com o fito de obter um maior número de dados possível para uma análise mais realista do comportamento da viscosidade dos óleos vegetais. A cada ajuste de velocidade do fuso (spindle), a temperatura da amostra em experimento foi medida. Os dados reológicos levantados para cada espécie de óleo propiciaram os cálculos de torque, tensão de escoamento e taxa de cisalhamento. Essas variáveis foram comparadas e confrontadas em forma de gráfico.

A obtenção do índice de refração ( $n$ ) das quatro amostras de óleos vegetais fez-se com o emprego do refratômetro Carl Zeiss 88246 , sendo as determinações realizadas em temperatura ambiente.

O ensaio de umidade dos óleos vegetais citados fez-se em duplicata para fins de confirmação dos resultados encontrados. Cada tipo de óleo foi aquecido por um período de uma hora em estufa de renovação e circulação de ar TE - 394/3, cujo fabricante é Tecnal. Depois de aquecidas, as amostras ficavam em dessecador por período de vinte e quatro horas.

\section{RESULTADOS}

Para cada tipo amostra foi determinado seu potencial hidrogeniônico $(\mathrm{pH})$ à temperatura ambiente; os resultados encontram-se na tabela 1, a seguir, a qual registra, ademais, os valores de massa específica $(\rho)$ obtidos por picnometria.

Tabela 1: Massa específica real e pH natural dos óleos e do sebo

\begin{tabular}{l|c|c|c}
\hline \hline \multirow{2}{*}{ Descrição } & $\mathbf{\rho}$ & Temperatura & $\begin{array}{c}\mathbf{p H} \\
\text { natural }\end{array}$ \\
\cline { 2 - 4 } & {$\left[\mathrm{kg} / \mathbf{m}^{\mathbf{3}}\right]$} & {$\left[{ }^{\circ} \mathbf{C}\right]$} & $\mathbf{2 0}\left[{ }^{\circ} \mathbf{C}\right]$ \\
\hline Óleo de semente de uva & 922,73 & 23,00 & 4,91 \\
\hline Óleo de rícino & 948,11 & 24,50 & 4,60 \\
\hline Óleo de arroz refinado & 911,16 & 25,80 & 5,43 \\
\hline Óleo de soja refinado & 915,54 & 20,10 & 6,79 \\
\hline Sebo bovino & 921,55 & 22,00 & $(3,00)$ \\
\hline \hline
\end{tabular}

Os resultados dos ensaios de determinação da tensão superficial (isto é: na interface ar/óleo) encontram-se sistematizados na tabela 2, já corrigidos para o valor de $2{ }^{\circ} \mathrm{C}$. Para apreciação visual da variabilidade das medidas plotou-se a figura 1.

Tabela 2: Tensão superficial média e seu desvio padrão amostral (corrigidos para 20 ㄷ)

\begin{tabular}{lcc}
\hline \hline Descrição & $\begin{array}{c}\text { Tensão superficial } \\
{[\mathrm{N} / \mathrm{m}]}\end{array}$ & $\begin{array}{c}\text { Desvio padrão } \\
{[\mathrm{N} / \mathrm{m}]}\end{array}$ \\
\hline Óleo de semente de uva: & 0,0334 & 0,00645 \\
\hline Óleo de arroz purificado: & 0,0334 & 0,00643 \\
\hline Óleo de rícino: & 0,0352 & 0,00678 \\
\hline Óleo de soja refinado: & 0,0333 & 0,00641 \\
\hline Sebo bovino: & 0,0268 & 0,00525 \\
\hline \hline
\end{tabular}




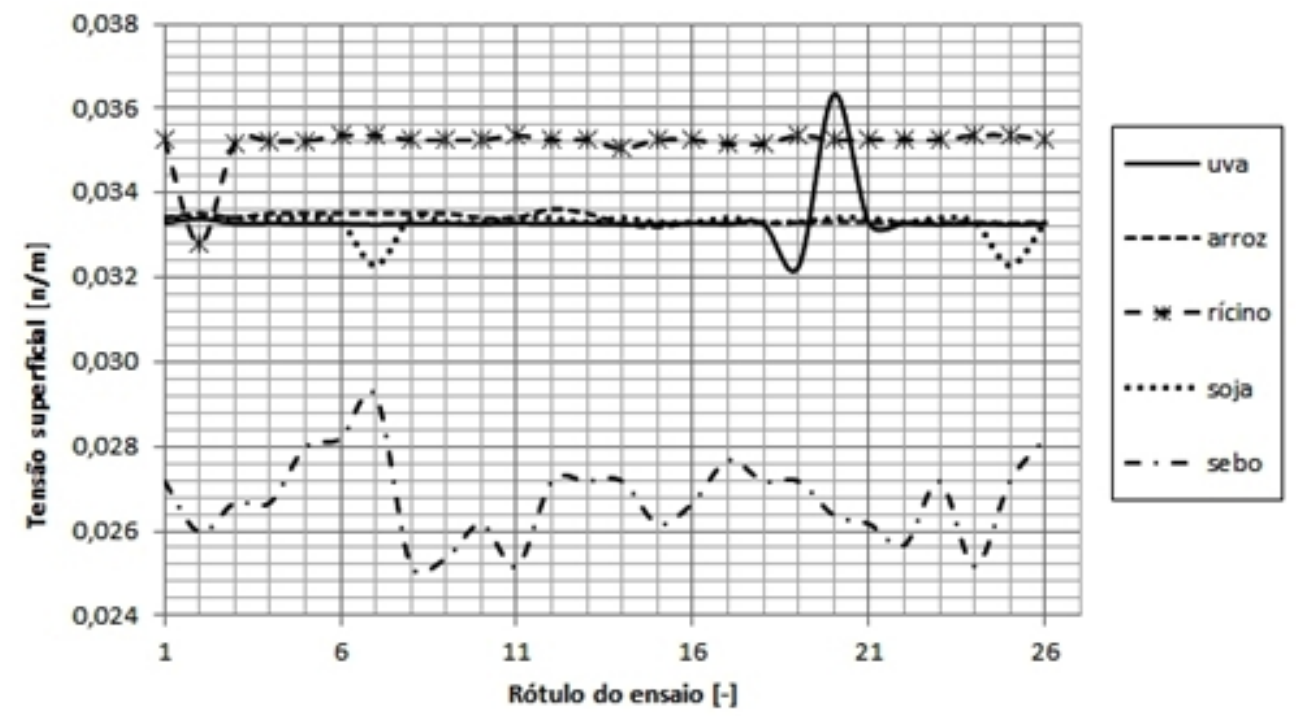

Figura 1: Comparativo da variabilidade dos valores de tensão superficial

Não somente devido a sua complexidade funcional e maior tamanho médio das cadeias hidrocarbônicas, o sebo bovino apresentou maior variabilidade tensiométrica. Esse comportamento também se observou devido à indisponibilidade de sistema de controle isotérmico do aparato (as medidas de tensão superficial com amostras de sebo eram feitas com aquecimento prévio, até a completa liquefação do mesmo a $60^{\circ} \mathrm{C}$ ). Como esperado, em vista de seu maior tamanho médio de cadeia, o sebo apresentou maior efeito tensoativo, resultando menor tensão superficial.

A maior tensão superficial do óleo de rícino provavelmente se deve à majoritária presença de éster do ácido ricinoleico (ácido 12-hidroxi-9-cis-octadecenóico), o qual ocorre naturalmente no óleo da mamona e que difere do ácido oleico por presença de hidroxila no décimo segundo carbono.

Os ensaios de viscosimetria permitiram o levantamento das curvas de viscosidade dinâmica aparente versus taxa de cisalhamento gerada pela rotação do fuso cilíndrico (spindle). Os gráficos correspondentes (Ver figuras de 2 a 6) mostram-se a seguir. A maior variabilidade das medidas a baixas taxas de cisalhamento está ligada a limitações do aparato. De um modo geral pode-se adotar sem grandes erros a categoria de fluidos newtonianos para os insumos estudados (com maior desvio no caso do sebo bovino, se comparado ao comportamento dos óleos vegetais).

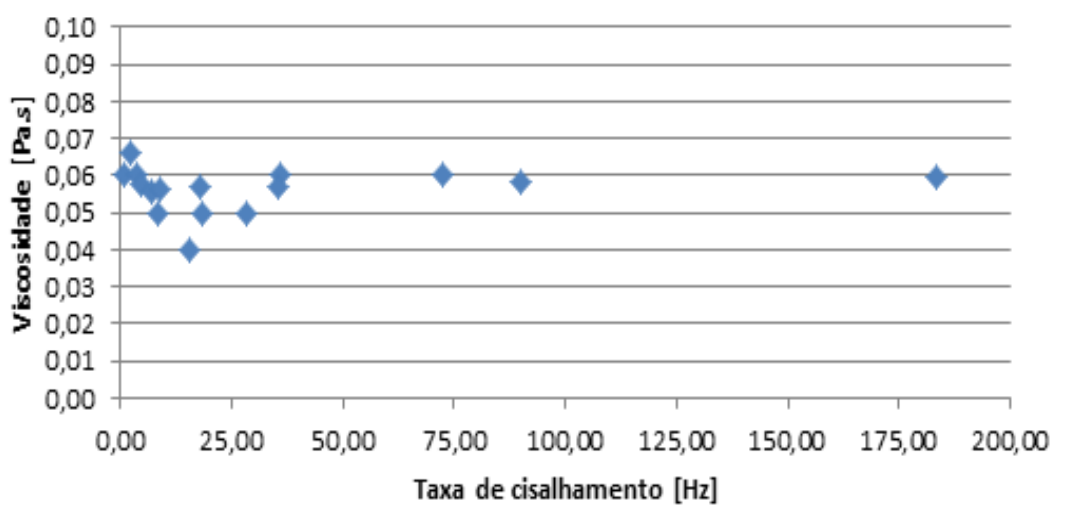

Figura 2: Viscosidade versus taxa de cisalhamento para o óleo de semente de uva a $25{ }^{\circ} \mathrm{C}$. 


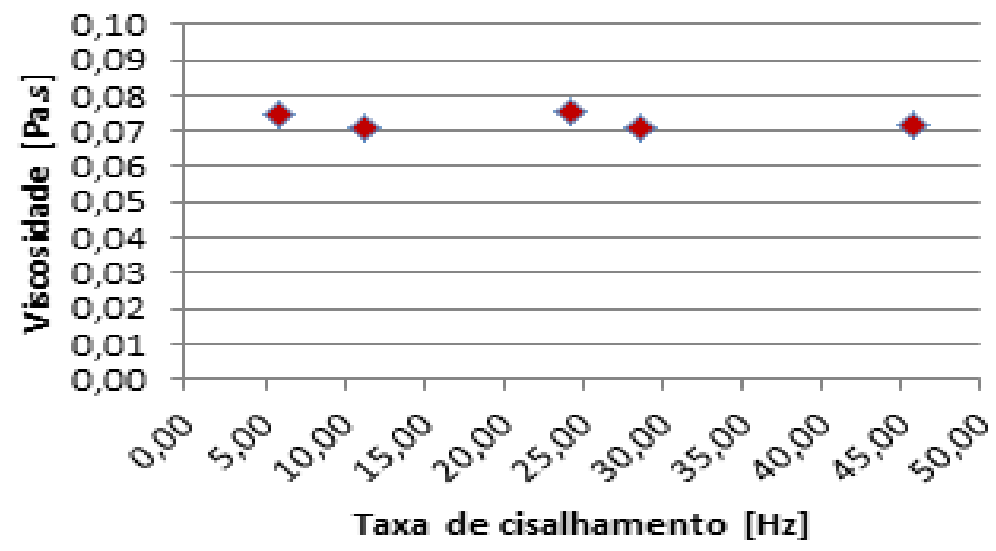

Figura 3: Viscosidade versus taxa de cisalhamento para o óleo de arroz refinado a $25{ }^{\circ} \mathrm{C}$

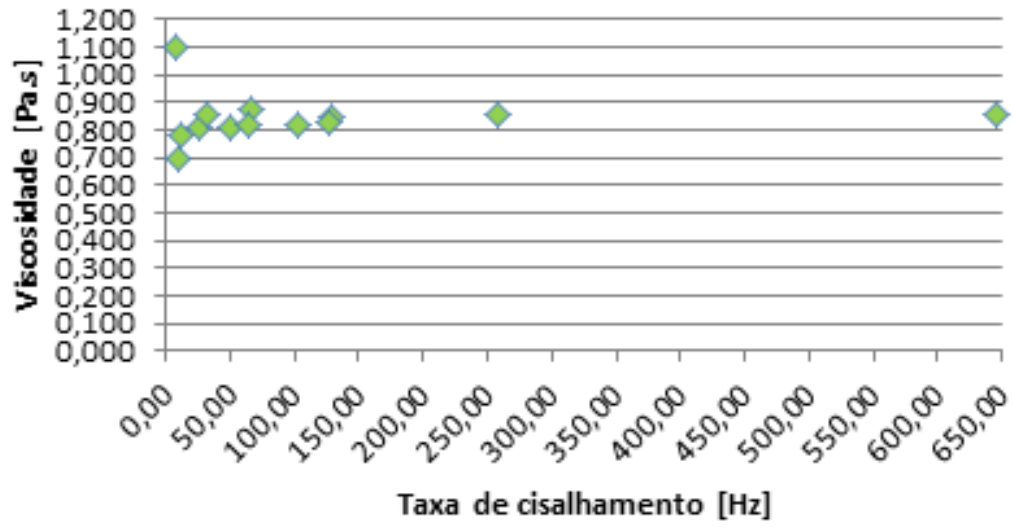

Figura 4: Viscosidade versus taxa de cisalhamento para o óleo de rícino a $25^{\circ} \mathrm{C}$

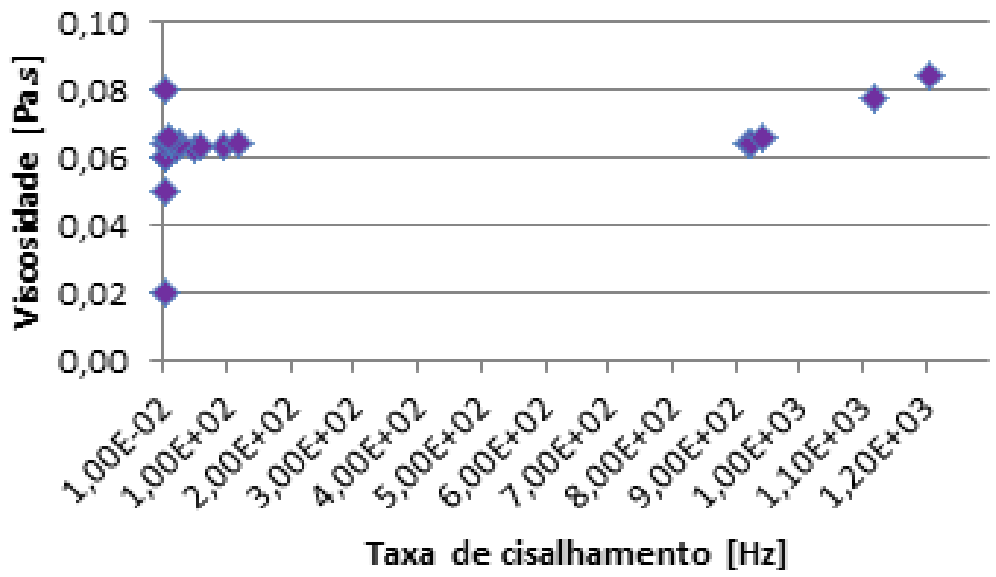

Figura 5: Viscosidade versus taxa de cisalhamento para o óleo de soja a $25^{\circ} \mathrm{C}$ 


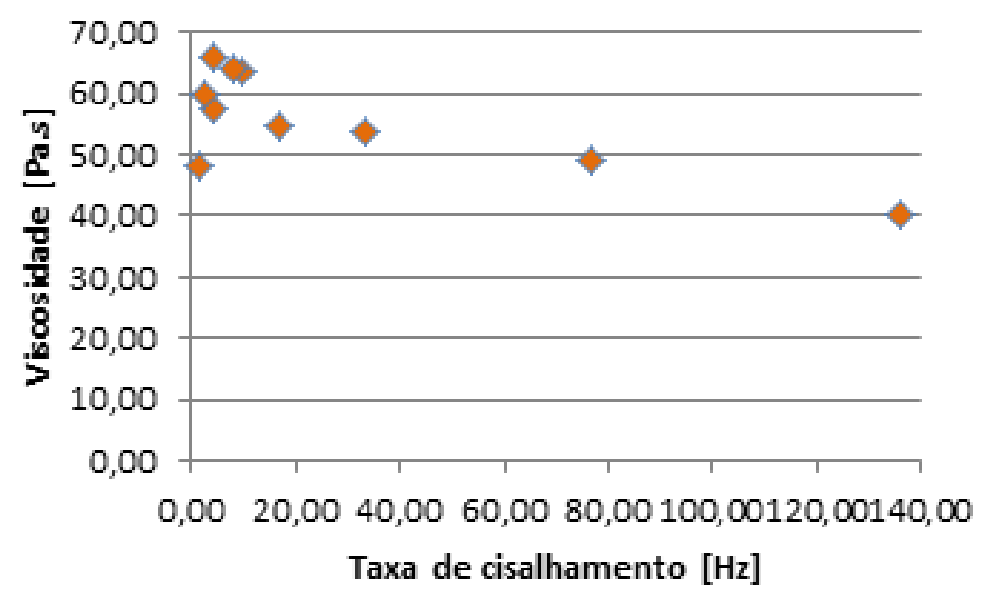

Figura 6: Viscosidade versus taxa de cisalhamento para o sebo bovino a $60^{\circ} \mathrm{C}$

No que tange ao índice de refração dos insumos estudados, somente foram ensaiados os óleos vegetais, à temperatura ambiente; os seguintes valores foram obtidos:

- $\quad$ Óleo de semente de uva: $n=1,479$;

- $\quad$ Óleo de arroz refinado: $n=1,476$;

- $\quad$ Óleo de rícino: $\mathrm{n}=1,482$;

- $\quad$ Óleo de soja refinado: $n=1,478$.

Outro indicador de qualidade de óleo para flotação é seu teor inerente de umidade, visto que a água catalisa reações de rancificação dos triglicerídeos componentes primaciais dos óleos vegetais. Tal efeito catalítico da água foi comentado, por exemplo, por Brandão (1992). Os resultados para os óleos estudados podem ser visto na tabela 3, a seguir.

Tabela 3: Média das determinações de umidade dos óleos vege
\begin{tabular}{lc}
\hline \hline Tipo de óleo: & Umidade média [\%] \\
\hline Arroz refinado & 0,110 \\
\hline Rícino & 0,118 \\
\hline Semente de uva & 0,004 \\
\hline Soja refinado & 0,024 \\
\hline \hline
\end{tabular}

\section{CONCLUSÃO}

Foi realizada neste estudo a avaliação de propriedades importantes de óleos e gorduras, visando ao estabelecimento valores de propriedades físico-químicas de insumos nacionais pertencentes a uma classe reagente de interesse a sistemas de flotação em espuma, qual seja a dos coletores aniônicos oxidrílicos (ácidos graxos e sabões).

Tais resultados físico-químicos, como os de densidade picnométrica, de tensão superficial, de viscosidade dinâmica, de índice de refração e de umidade permitiram estabelecimento de propriedades relevantes das amostras e confrontá-las com as que existem na literatura. 
O trabalho aqui apresentado faz parte de uma linha de investigação que vem sendo seguida e que ainda se encontra em andamento, em especial no levantamento de índice de refração, índice de saponificação (uma medida da intensidade de reação de saponificação em meio cáustico) e índice de iodo (uma medida do grau de instauração das ligações carbônicas nos triglicerídeos). Em sequência, pretendem-se realizar também trabalhos empregando os mesmos óleos e gordura em sistemas reais de flotação aniônica (em especial na flotação aniônica direta de minério de ferro e na flotação aniônica direta de minérios apatíticos).

\section{AGRADECIMENTOS}

Os autores agradecem ao CNPq, à UFOP, à Fundação Gorceix, pelo suporte, e ao eng Adhebar Soares Jr., pela ajuda na execução da fase experimental deste trabalho.

\section{REFERÊNCIAS BIBLIOGRÁFICAS}

1. AZEVEDO, J. C. S. Estudo de Processos de Saponificação do óleo de arroz e do óleo de rícino. Belo Horizonte: Universidade Federal de Minas Gerais. 1994. 42 p.

2. BRANDÃO, P. R. G. \& PEREIRA, A. M. T.. Ácidos Graxos Insaturados (Isômeros Cis-Trans) Na Flotação Seletiva de Minerais Levemente Solúveis. In: CIMINELLI, V.; SALUM, M. J. G. (Org.). Flotação: Fundamentos, Prática e Meio Ambiente. 1ed. Belo Horizonte, MG: Associação Brasileira De Tecnologia Mineral, 1992, V. 1, p. 19-38.

3. BRASIL. Ministério da Indústria e do Comércio. Produção de Combustíveis Líquidos a Partir de Óleos vegetais. Brasília: MIC/STI/CIT. 1985.364 p.

4. CAIRES, L G. Óleos vegetais como matéria-prima para coletores. Belo Horizonte: Universidade Federal de Minas Gerais. 1992. 42 p.

5. FORNAZIERI JR., A. Mamona - uma Rica fonte de Óleo e de Divisas. São Paulo: Ícone. 1986. 72 p.

6. JAMIESON, G. S. Vegetal Fats and Oils (American Chemical Society Monograph Series). New York: Reinhold.1943. 512 p.

7. LUZ, A .B; SAMPAIO, J. A. \& FRANÇA, S. C. A. Tratamento de Minérios - 5á edição. Rio de Janeiro: CETEM/MCT, 2010.

8. MORETTO, E. \& ALVES, R. F. Óleos e Gorduras Vegetais (Processamentos e análises). Florianópolis: EUFSC. 1986.180 p.

9. POSSA, M. V; NASCIMENTO, C. R. Reologia no Tratamento de Minérios. In: LUZ, A. B; SAMPAIO, J. A \& FRANÇA, S. C. A. (ed.). Tratamento de Minérios - 5a edição. Rio de Janeiro: CETEM/MCT, 2010. cap.14, p.597-631.

10. SHOEMAKER, D. P.; GARLAND, C. W.; NIBLER, J. W. Experiments in Physical Chemistry. New York: McGraw-Hill, 1996 - 778 p. 